\title{
Abasto y consumo de pescados y mariscos en Guadalajara durante el siglo XVII
}

\section{Supply and consumption of fish and shellfish in Guadalajara during the 17 th century}

\author{
René de León Meza* \\ UNIVERSIDAD DE GUADALAJARA \\ http://doi.org/10.22370/pe.2020.10.2660
}

\section{RESUMEN}

Este artículo demuestra que en la ciudad de Guadalajara durante el siglo XVII hubo un alto consumo de pescados y mariscos determinado en gran medida por la imposición de la iglesia católica a no consumir carne roja durante los días de vigilia, cuaresma, viernes y sábado. Comprueba que estuvo muy bien abastecida gracias por un lado a su cercanía con la laguna de Chapala y el río Grande o Santiago y por otro al ser punto de tránsito obligado de los mariscos que venían de tierra caliente rumbo a otras partes de la Nueva España. Esboza como gracias a la importancia económica que alcanzó ese circuito comercial se implementó un sistema de cobro de alcabalas para los productos considerados de lujo, mientras que otros estimados como un bien común quedaron exentos de pagarla. Termina haciendo una serie de propuestas para estudios futuros entorno al comercio colonial de estos productos.

Palabras clave: pescados, mariscos, abasto, consumo, conventos

\section{Abstract}

This article demonstrates that in the city of Guadalajara during the seventeenth century there was a high consumption of fish and shellfish largely determined by the imposition of the Catholic Church not to consume red meat during the days of vigil, lent, Friday and Saturday. Check that it was very well stocked thanks on the one hand to its proximity with de Chapala lagoon and the Río Grande or Santiago and on the other being a forced transit point for seafood that came from hot land heading to other parts of New Spain. It outlines how, thanks to the economic importance of this commercial circuit, it is implemented in a collection system of alcabalas for affected luxury products, while other estimated as a common good will remain exempt from paying it. He ends up making a series of proposals for future studies on the colonial trade in these products.

Keywords: fish, shellfish, supply, consumption, monastery 
INTRODUCCIÓN

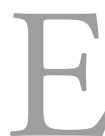

n 1972 el profesor Carlos Sempat al analizar el funcionamiento del mercado interno de varias regiones del Perú resaltó que los historiadores ignoraban o depreciaban el estudio de la actividad pesquera en aquel territorio a pesar de la importancia económica que había alcanzado en el siglo XVII (Assadurian, 1983: 219). A casi cincuenta ańos de aquel aserto encuentro que esa tendencia se mantiene vigente en la historiografía colonial de México. La abundante bibliografía que analiza el abasto, consumo y mercados de distintas regiones de la Nueva España se ha enfocado en estudiar otro tipo de alimentos como granos, carne de res, cerdo, chivos y ovejas. Pocos autores esbozan el consumo de pescados y mariscos, sus rutas de suministro así como los centros de consumidores pero no dedican ni siquiera un capítulo al estudio de este circuito comercial. ${ }^{1}$ Caso contrario sucede con la historiografía española que es muy abundante en esta temática, con estudios específicos para varias regiones en los siglos XVII-XVIII y el consumo el consumo de determinada especie de mariscos. Véanse como muestra de esto último los trabajos de (Meijede, 1980), (Cubillos, 1998), Piquero y López, 2008), (Torrija, 2009), (Vázquez, 2009) y (Marchena, 2010).

En el caso específico de la historiografía jalisciense, escasos son los autores que constatan la existencia de una intensiva explotación de pescados y mariscos en el reino de la Nueva Galicia pero sin profundizar en su funcionamiento y parcamente bosquejan el sistema de abasto de estos productos para el consumo de los habitantes de Guadalajara.

Woodrow Borah (1994: 95-99) en su trabajo sobre los tributos que pagaban los pueblos de indios a la corona en la segunda mitad del siglo XVI destaca a las provincias de Ixtapa y Centipac como abastecedoras de pescado seco y ostiones pero sin aclarar a quiénes abastecían. La historiadora Laura Rueda (2009: 336) menciona la importancia de la producción pesquera en los siglos XVI y XVII así como el intenso tráfico de pescados y mariscos por toda la Nueva Galicia y la Nueva España, limitándose a mencionarlo pero 
sin aportar mayores detalles. Dos historiadores ya clásicos para la historia de Guadalajara colonial nos acercan un poco más al relevante consumo de estos productos en la capital neogallega y el circuito establecido para su abasto, aunque ninguno de ellos dedica más de una cuartilla al tema (Calvo, 1992: 271-272; Serrera, 1992: 267 y Serrera, 1974: 139).

Aunadoalospocosestudiosantesmencionados, eldesconocimiento de las fuentes documentales de la época ha ocasionado que algunos historiadores hayan llegado a afirmar erróneamente que el consumo de pescados y mariscos en Guadalajara era mínimo (Reynoso, 2016: 61-65). Las abundantes descripciones geográficas coloniales más la información resguardada en los distintos archivos de esta ciudad confirman la existencia de un importante circuito comercial desde el siglo XVI que funcionaba mediante la pesca, conservación, traslado y venta de una amplia variedad de especies acuáticas tanto de mar, ríos y lagunas capaz no solo de abastecer a la capital neogallega sino a otros importantes mercados consumidores como Zacatecas y la ciudad de México.

Este artículo tiene como objetivo primario analizar el sistema de abasto de pescados y mariscos para Guadalajara en el siglo XVII, la organización administrativa que se impuso para su distribución dentro de la ciudad mediante el establecimiento de puntos de venta, precios obligatorios, políticas para combatir la reventa (regatonería) y el establecimiento del cobro de alcabala a partir de la importancia económica que había alcanzado hacia el último tercio de esa centuria esta actividad comercial. El segundo objetivo se centra en estudiar la cantidad de días y la variedad de especies que se vendían en la ciudad de Guadalajara para intentar demostrar lo mucho que sus habitantes consumían este alimento.

Las hipótesis planteadas en este artículo sostienen primero, que los habitantes de la ciudad de Guadalajara durante el siglo XVII tuvieron un alto consumo de pescados y mariscos ocasionado por la imposición de la iglesia católica a no comer carne roja durante muchos días al año y aunque es verdad que no obligó al consumo de éstos, sí lo potenció. Segundo, la capital neogallega estuvo muy bien 
abastecida ${ }^{2}$ de esos productos debido a la demanda ocasionada por el anterior planteamiento pero sobre todo por su ubicación geográfica cercana a dos fuentes abundantes de abastecimiento como la laguna de Chapala y el río Santiago, además de ser el paso obligado hacia otros grandes centros consumidores como la ciudad de México, Zacateas y la Nueva Vizcaya. De manera que los arrieros al pasar por esta ciudad para llevar a vender pescados y mariscos secos y salados, aprovechaban para surtirla de esos mismos productos. Y tercero, La industria pesquera neogallega que fue predominantemente indígena en sus inicios (siglo XVI) irá alcanzando tal importancia económica que provocará la incursión de los españoles quienes desplazarán gradualmente a los primeros mediante el desarrollo de grandes pesquerías.

El método hermenéutico me permitió analizar la gran diversidad de fuentes documentales de la época para entender distintos procesos evolutivos de este circuito mercantil que servirán para demostrar los planteamientos centrales de este escrito. El cruce de información emanada de las distintas dependencias gubernamentales (cabildo, caja real, audiencia) sirvió para vincular ciertas políticas económicas para asegurar el abasto y consumo de los habitantes de la ciudad.

\section{Fuentes de abastecimiento para Guadalajara}

La abundancia y variedad de pescados y mariscos que comieron los habitantes de Guadalajara a lo largo del siglo XVII se obtuvieron principalmente de la laguna de Chapala, lago de Cajititlán, del río Santiago y desde varias provincias del litoral del Pacífico entre las que destacan Tequepexpan y Centipac. La laguna de Chapala que en aquel entonces tenía una longitud de 30 leguas y una circunferencia de 60, fue el principal proveedor de pescado blanco, bagre y en menor medida charales. Literalmente todos los pueblos de su ribera (Jamay, La Barca, Cuitzeo, Poncitlán, Atotonilco, Ayo el Chico, Ayo el Grande, Mezcala, Ocotlán, Jocotepec y Chapala) se insertaron en esta economía pesquera. La abundancia de esa laguna permitía abastecer mercados distintos a la ciudad de Guadalajara. Por ejemplo en 1623, un pescador del pueblo de Jamay vendió en 
una sola partida mil arrobas (11,500 kilos) de pescado bagre para ser consumido en la ciudad de México. (Biblioteca Pública del Estado de Jalisco, Real Audiencia de Guadalajara (en adelante BPEJ-RAG) Civil-469-17-7837)

Del lago de Cajititlán en cambio se sacaba sobre todo mucho charal y poco pescado blanco. Varios cronistas coloniales nos dejaron detalladas descripciones de estas especies que desafortunadamente algunas ya desaparecieron y otras están en peligro de extinción. El obispo de Guadalajara Alonso de la Mota y Escobar escribió en 1605 que el pescado blanco era conocido por los indígenas locales como Amilote y que era:

mayor de media vara, su carne excede en blancura a una leche cuajada, el gusto como de carne tan delicada, no es apetitoso, sino se ayuda de condimentos, es sumamente sano que se da a cualquier enfermo, comese de una vez muchos sin recelo que dañe. No me acuerdo de haber comido en Castilla pece que se le paresca, sola la azedia de Sevilla le remeda algo en lo delicado, no tiene espinas más que sola la de la armazon. Ay mucha cantidad en su tiempo y corrompese muy breve, no admite sal por su delicadeza porque con ella se engarrota y jamás la despide aunque le remogen. (Mota, 1993: 30).

Por su parte, Domingo Lázaro de Arregui señaló en 1621 que el pescado blanco era "al modo de sardina, los más pequeños sin escamas y es muy blanco y de buen gusto..." (Arregui, 1980: 83). Matías de la Mota Padilla cronista de Guadalajara a mediados del siglo XVIII destacó lo delicioso del pescado bagre y del blanco, así como las medidas que alcanzaban, siendo el primero desde una cuarta hasta vara y media, mientras que el segundo apenas llegaba a media vara. (Mota, 1973: 31).

El equipo extractivo de un importante abastecedor de pescado a Guadalajara desde la laguna de Chapala se componía hacia el último tercio del siglo XVII por dos canoas de madera con sus chinchorros, doce pescadores indios bajo el mando de un capitán 
y un espańol que era el mayordomo encargado de todo el proceso. El propietario contaba además con una recua de mulas al mando de dos arrieros encargados de llevar el producto a la capital neogallega en donde se lo entregaban a un comerciante para su venta. El gasto del empresario era una constante pues necesitaba comprar alimentos tanto para sus trabajadores como para las mulas y la renovación de estas cada determinado tiempo. Tenía que adquirir muy seguido hilo para hacer nuevos chinchorros ya que cada uno de ellos duraba entre tres y cuatro meses (en 1672 una libra de hilo para pescar costaba un peso y medio). Sobre todo gastaba en salarios. El mayordomo y capitán ganaban diez pesos mensuales, los pescadores y mozos de recua entre 5 y 6 pesos más sus raciones de carne y maíz. Al menos en el trienio de 1672-74 la venta de su pescado en la plaza de Guadalajara fluctuaba entre los 12 y 16 pesos por día, lo que significaba un ingreso promedio anual de 2,040 a 2,720 pesos; pero como sus gastos iban de 1,600 a 1,800 pesos, su ganancia neta variaba de 400 a 800 por ańo. (BPEJ-RAG-Civil 8-17-113).

Durante todo el ańo se llevaba a vender pescado a Guadalajara pero era en la época de cuaresma cuando más se incrementaba la demanda siendo necesario extender las jornadas laborales durante las noches (los salarios se duplicaban en ese tiempo). Esto ocasionaba que también aumentara la competencia pues tanto espańoles como indios se insertaban en la pesca haciendo más difícil esta, lo que obligaba a los trabajadores a remar hacia lo más profundo de la laguna doblando así el trabajo. Una vez terminada la cuaresma, la demanda volvía a su normalidad pero por ser ya temporada de calor el pescado que más se obtenía el bagre pues el blanco se sumergía hasta lo profundo en busca de aguas más frías lo que dificultaba su captura. De acuerdo a testimonios de pescadores de esa época para obtener apenas una carga de pescado blanco durante esa temporada de calor era necesario que hicieran de cinco a seis lances de chinchorro. (BPEJ-RAG-Civil 8-17-113).

Del río Grande o Santiago aunque hoy parezca increíble por lo contaminado que está, se obtenía una amplia variedad de pescados como bagres, truchas, sardinas, bocudos, pejerreyes y róbalos que se 
internaban del mar "cuya comida era tan regalada como la del sollo en Castilla” (Mota, 1993: 29). El cronista del siglo XVII Antonio Vázquez de Espinoza escribió que a tres leguas de Guadalajara se encontraba el río Grande "de mucho y regalado pescado" y agregaba además que en la comarca de la ciudad existían muchos ríos y abundancia de pescado (Vázquez, 1948: 172). El mapa 1 muestra la riqueza acuífera de la Nueva Galicia y permite al lector apreciar todas las fuentes disponibles para la obtención de estos alimentos y entender de cierta forma lo bien abastecida que se encontraba la capital neogallega al estar prácticamente rodeada de ríos, lagunas y por el litoral del pacífico.

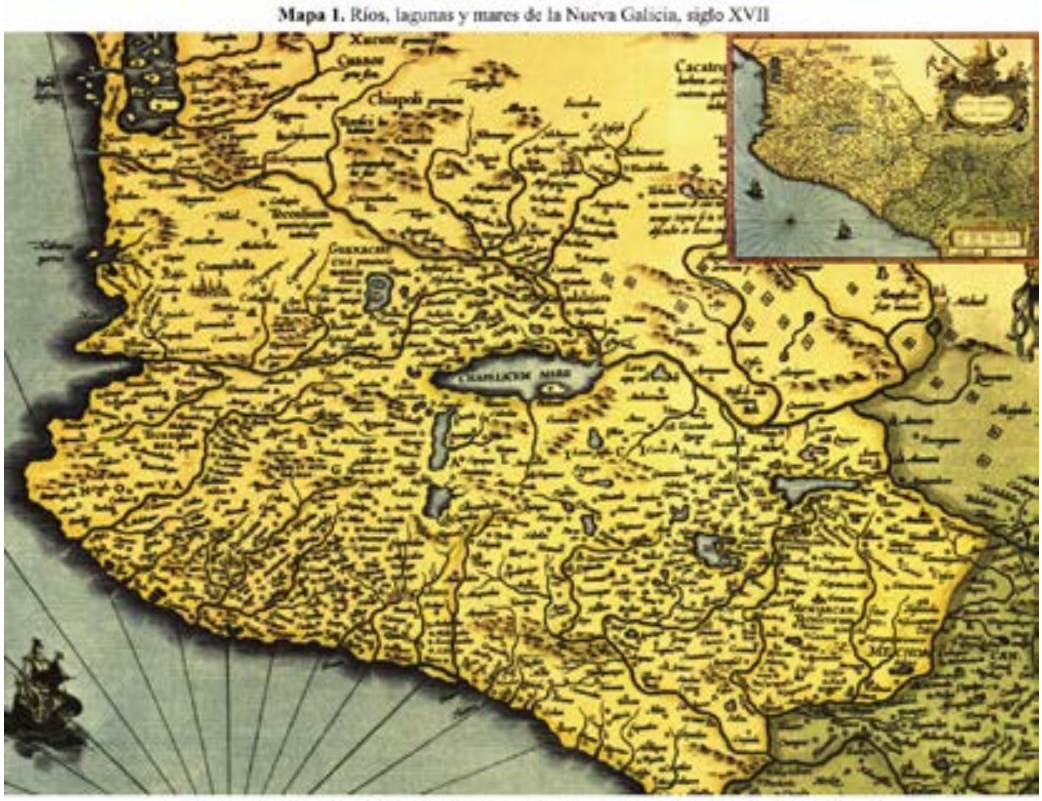

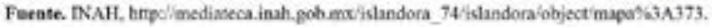

Del Océano Pacífico y de los esteros que se formaban por la desembocadura de varios ríos, específicamente en las provincias de Acaponeta, Tequepexan y Centipac, se pescaba mucho camarón, ostiones, lisas, róbalos, pargos, puyeques (que eran muy parecidos a las mojaras) y muchas tortugas de las que se vendían sus huevos 
y su carne en tasajos (Arregui, 1980: 83-84). Tan solo en el pueblo de Acaponeta los 180 indios casados que ahí vivían a principios del siglo XVII se dedicaban en gran medida a la pesca tanto en el mar como en los esteros de donde obtenían jugosas ganancias por su venta (Mota, 1993: 114). Pero probablemente la principal región abastecedora de mariscos a Guadalajara fue la de Centipac como lo atestiguan los documentos encontrados. El mejor ejemplo de lo anterior lo encontramos a lo largo de la segunda mitad del siglo XVII en la familia de los condes de Miravalle que explotaron una gran pesquería en la boca del río Iscuintla en la provincia de Centipac y otra en la laguna de San Pedro Lagunilla en la jurisdicción de Tequepexpan.(Archivo de Instrumentos Públicos de Guadalajara (en adelante AIPG), Tierras y Aguas, 1era. Col., Vol. 3, fojas 337$340 f)$. El mapa 2 permite visualizar la riqueza acuífera de esta región al hacer frontera con el Pacífico, tener en sus tierras al menos una laguna importante y estar cruzada por varios ríos que desembocaban en el mar, lo que le brindaba las condiciones óptimas para el desarrollo de infinidad de pesquerías.

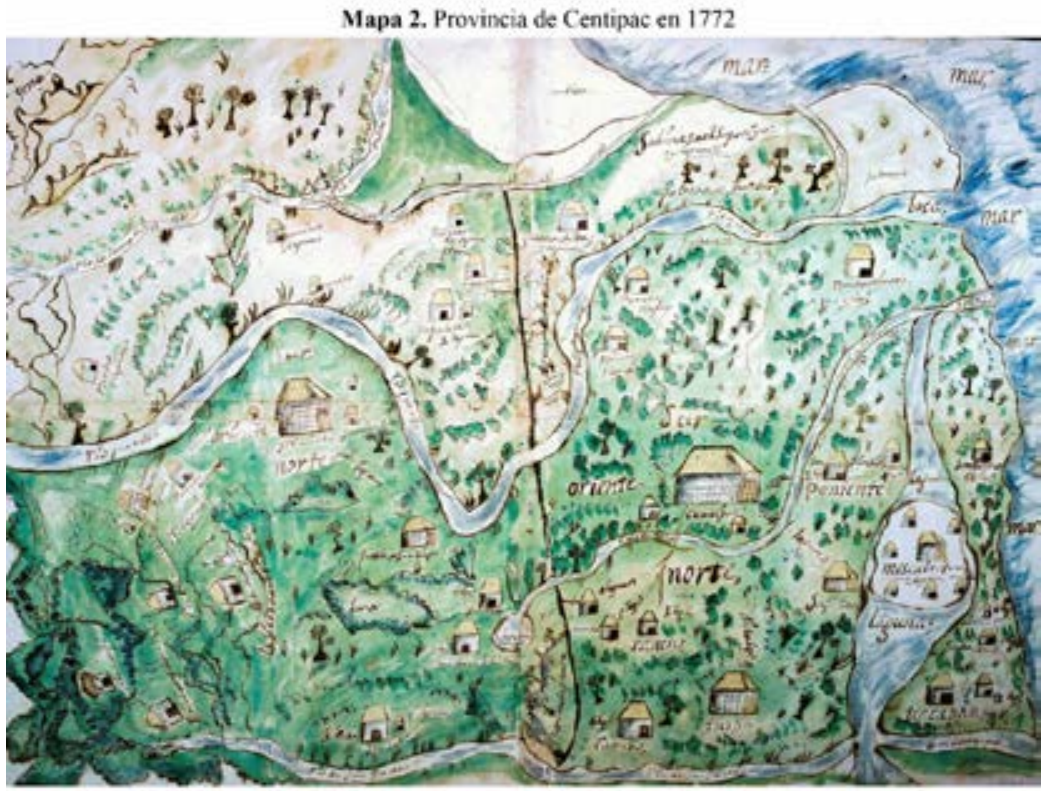

Fuente. AGI, ES,41091,AGI/27,17//MP-MEXICO,284, 
Los mariscos de tierra caliente llegaban a Guadalajara vía Tepic, en forma seca o salada metidos en bultos transportados por mulas. El pescado debía de venir bien envuelto en sal y el camarón entero pues si llegaba molido no lo aceptaban los compradores. La capacidad de carga de cada mula era de 161 kilos pues cada carga se componía de 14 arrobas (una arroba pesaba 11.5 kilos). El traslado de Tepic a Guadalajara se cobraba a razón de tres pesos y medio por cada mula. Una recua compuesta de 18 mulas necesitaba que fuera guiada por dos mozos a los que se les pagaba 15 pesos por el viaje. A veces ocurría que mariscos con destino a otros lugares como Guanajuato, Zacatecas, Querétaro o Ciudad de México, al pasar por Guadalajara se quedaban por diferentes circunstancias y entonces eran vendidos aquí. $^{3}$

\section{Consumo y Reglamentación}

Analizar el consumo de pescados y mariscos en Guadalajara durante el siglo XVII con cifras exactas es imposible porque no hay registros sobre los montos anuales que ingresaban de esos productos a la ciudad y los datos sobre su número de habitantes son muy imprecisos aunque con una clara tendencia a la alza a lo largo de esa centuria lo que nos indica de manera natural una mayor demanda de alimentos. Para 1602 el número de vecinos era de 60 y el total variaba entre los 1,400 y 1,800 habitantes (Borah, 1994: 36). Tres años después el obispo Alonso de la Mota y Escobar (1993: 25) señalaba que habitaban la ciudad 173 vecinos que con sus familias y la gente de hábito sumaban 500 españoles más otro tanto de esclavos negros y mulatos, esto sin contar a las otras razas. A principio de la década de los ańos 20 los vecinos espańoles eran 200 y cincuenta ańos después llegaron a quinientos (Arregui, 1980: 115; Archivo General de Indias (en adelante AGI), Guadalajara 13 R1 N. 8). Otros datos al respecto nos los proporciona el profesor Calvo quien calcula que para mediados del siglo los habitantes llegaban a casi cuatro mil y para inicios del siglo XVII vivían en la ciudad entre nueve y diez mil habitantes (Calvo, 1992: 47-52). 
Con lo anterior nos podemos dar una somera idea del mercado consumidor que representaba Guadalajara, ahora bien ¿cómo saber si estaba bien abastecida de pescado y mariscos y sí sus habitantes los consumían con bastante frecuencia si no tenemos cifras? Considero que ciertos elementos nos dan la respuesta. Uno de ellos es la práctica común que implementaron distintos funcionarios reales para obligar a los indígenas a llevarles gratuitamente pescados a su casa para su consumo mediante el formato de servicio personal, repartimiento y tequio. Los oidores de la Audiencia exigían pescado y otros alimentos a los habitantes del pueblo de Mexicaltzingo a pesar de la queja que estos presentaron en 1620 en la que argumentaban que estaban exentos de este servicio personal como descendientes de los mexicas que habían ayudado a la conquista de Guzmán. Era tan fuerte esta imposición que en junio de 1621 el rey mandó una cédula real para prohibir que se les siguiera pidiendo alimentos y servicios a los indios. (AIPG, Tierras y Aguas, 1era. Col., Vol. 356, fojas $23 \mathrm{v}-24 \mathrm{f}$ ).

Pese a esta prohibición la práctica continuó habitualmente. En 1668 el presidente de la Audiencia de Guadalajara reconocía que era costumbre inmemorial que se trajera pescado de repartimiento a los "señores de la real Audiencia y a él mismo" tal y como ocurría en Madrid con los señores ministros a través del repeso. Afirmaba que en cumplimiento de aquella cédula real no consentiría que se siguiera entregando pescado hasta que el Real Concejo definiera la situación. (AGI, Guadalajara, Cartas de Audiencia 11R.10 N 84). En realidad la respuesta del presidente Miguel de Agurto era un "lo acato pero no lo cumplo" pues nada hizo para remediarlo a pesar de las constantes quejas de indígenas de diferentes pueblos. Por ejemplo en 1672 los naturales de la jurisdicción de Tacotán se quejaban de que su corregidor los obligaba a pescar bagre para él. (AIPG, Libros de Gobierno, vol. 1, exp. 65, foja 28f).

Otros funcionarios que se beneficiaron de recibir pescado para su alimento fueron los procuradores del Ayuntamiento de Guadalajara encargados de vigilar el buen funcionamiento de los mercados que se instalaban en las plazas de la ciudad. A manera de reconocimiento 
a su labor, el Cabildo aceptó continuar con una "vieja costumbre" de entregarles los viernes y sábados una o dos sartas de pescado blanco comprometiéndose además a mantener este beneficio a perpetuidad; aunque en este caso la ciudad era quien cargaba con el costo a través del ramo de propios.(Archivo Histórico Municipal de Guadalajara (en adelante AHMG), Ayuntamiento, Ay paquete 2 , legajo 25). Tenemos entonces que en aquella centuria un número indeterminado de empleados reales aseguraban para su alimentación una cantidad también desconocida de estos géneros.

Ahora bien, dos fuentes distintas me permiten constatar que en Guadalajara se vendía pescado fresco al menos 170 días al año, cifra que surge al sumar los viernes, sábados, días de vigilia y cuaresma ${ }^{4}$ y que demuestra como el alto consumo de pescados y mariscos estuvo determinado por la aceptación o resignación de la imposición religiosa a no comer carne roja. Lo anterior no implicaba que en otras épocas del año no se vendiera pescado fresco u otra clase de mariscos secos o salados pues al menos estos últimos se encontraban habitualmente en las tiendas fijas de la ciudad.

En la Biblioteca Pública del Estado de Jalisco se resguarda un libro de gastos del convento de San Agustín de Guadalajara que abarca un periodo de 1653 a 1688 en el que se asienta entre otras cosas, los días que tenían definidos para comer pescados y mariscos y las cantidades de dinero que gastaban en ellos. Destacan por supuesto la cuaresma, los viernes, sábados y vigilias, siendo la primera en donde por obvias razones más se consumía, aunque es notorio que en todos los meses lo hacían. Mes tras mes, durante esos 36 años se registraron las compras de esas especies para su consumo, aunque hay que aclarar que no siempre los datos son específicos lo que impide precisar algunas cantidades. Por ejemplo en las compras por mes solo indica "pescado para la vigilia", "pescado, róbalo, bagre, camarón para la cuaresma”, "pescado, legumbres, huevos, arroz para los viernes, sábados y vigilia” o "camarón y róbalo para la fiesta de nuestro santo patrono"; sólo en muy pocos meses se aclara el dinero pagado exclusivamente por pescado y en otros tantos la cantidad del mismo. (BPEJ-Fondo Manuscritos, núm. 64). 
A pesar de las limitantes de la fuente su valía para este artículo es que demuestra la fuerte presencia de estos alimentos en la dieta de los agustinos de Guadalajara y permite conocer un aproximado de lo que anualmente gastaban en comprarlos, tal como lo demuestra la gráfica 1. Ahora bien, si hacemos un ejercicio para desglosar por mes las compras de pescados y mariscos en ese convento resaltarán de inmediato los meses de febrero, marzo y abril debido a su vínculo con la cuaresma, pero sobre todo destaca el consumo constante a lo largo de todo el año. La gráfica 2 compuesta de diez años que se tomaron aleatoriamente demuestra el anterior aserto. Supongo entonces que las demás órdenes que existieron en la ciudad tanto de hombres como de mujeres hicieron algo parecido pero de momento queda pendiente su comprobación.

Gráfica 1. Gasto anual de pescados en el convento de San Agustín de Guadalajara.

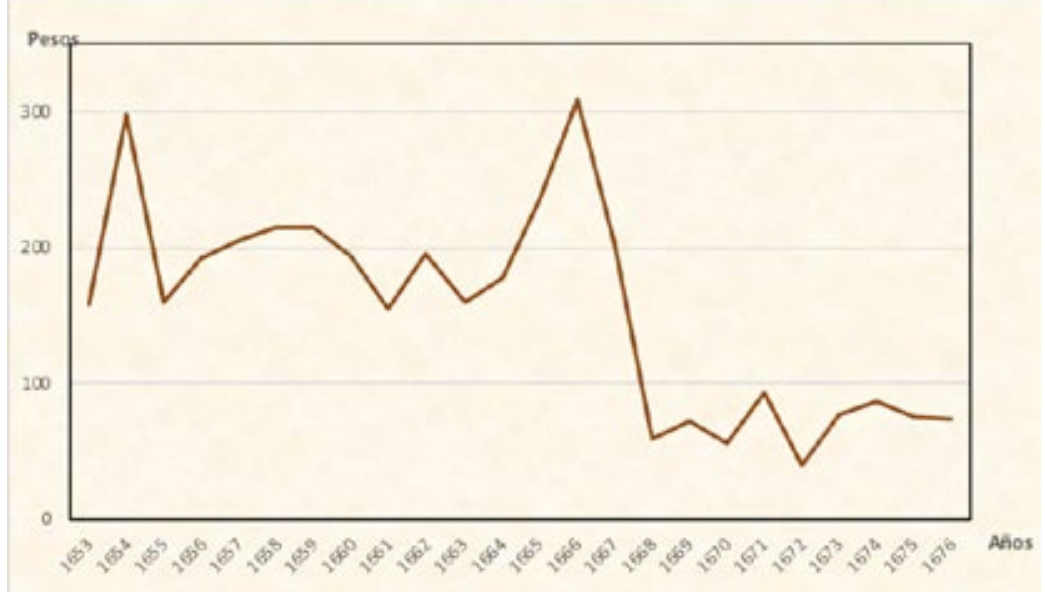

Fuente: BPEJ, Manuscritos, núm. 64. 
Gráfica 2. Gasto mensual de pescado en el convento de San Agustín de Guadalajara (i 656-i 666).

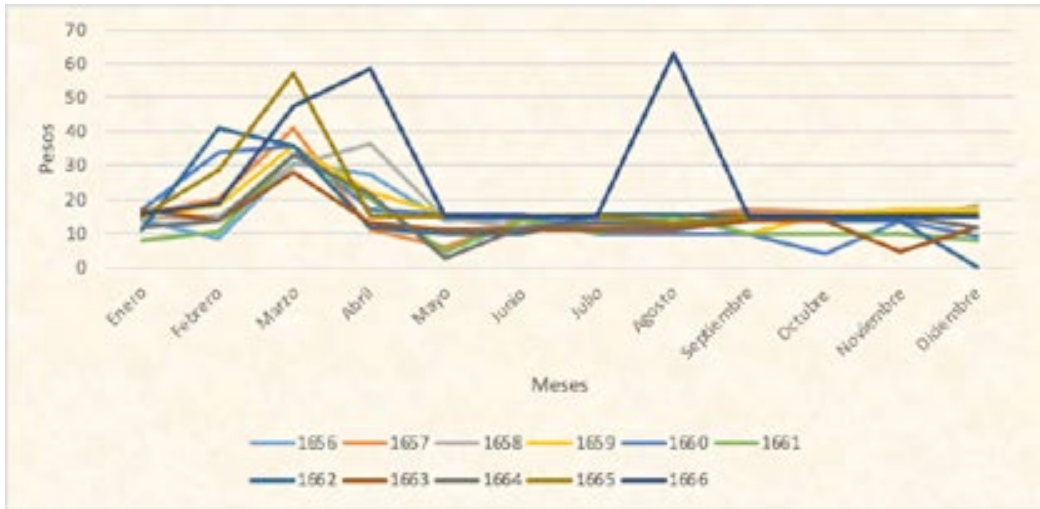

El otro documento que comprueba lo mucho que se consumía pescado en Guadalajara está fechado en 1674 y al igual que el anterior demuestra por distintas razones, que 170 días al año se vendía pescado fresco en la plaza principal de la ciudad, siendo estos días los que marcaba la iglesia católica para no comer carne. La bondad de esta fuente permite conocer además que el pescado que más se vendía era el blanco seguido del bagre en una proporción de tres a uno. Según los vendedores de ese tiempo, esto se debía a que el bagre era considerado de mala calidad y pocas personas lo consumían. La desventaja del pescado blanco era que se echaba a perder muy pronto sobre todo en las épocas de calores y por lo tanto la gente se veía obligada a comprar bagre pues este se conservaba más tiempo. No he encontrado hasta el momento ningún dato sobre el precio en que se vendían estos productos, pero este debió ser muy bajo si se toma en cuenta que no se consideraba un negocio lucrativo pues su venta se veía como un bien a la comunidad por ser uno de los principales alimentos de la gente pobre.(BPEJ-RAGCivil 8-17-113).

De hecho ni siquiera se les cobraba alcabala a los vendedores porque existía una especie de acuerdo tácito que consistía en que estos regalaban el pescado que no se les vendía a los conventos, a la 
cárcel y a los pobres para su alimentación. Durante la segunda mitad del siglo XVII se calculaba que un tercio del total introducido a las plazas no se vendía y ese era el que se donaba, pero es imposible conocer cifras aunque sea cercanas. Se sabe que para 1652 había en la ciudad 110 religiosos repartidos en 7 conventos pero falta sumar el número de religiosas. (AGI, Guadalajara 10 R.5 N. 21). El guardián del convento de San Francisco y el prior del de Santo Domingo declaraban por ejemplo que las cantidades de limosna que un vendedor les regalaba iban de 2 a 4 pesos pero se ignora a cuánta cantidad de pescado equivalía y la regularidad con que se les daba. (BPEJ-RAG-Civil 8-17-113).

Un último elemento que reafirma el consumo en Guadalajara de los alimentos aquí estudiados durante el siglo XVII tiene que ver con la organización administrativa para su venta que era regulada por el Cabildo y por la Aduana. Es importante destacar que los mariscos secos y salados que provenían de la tierra caliente, en particular de Tepic, Centipac y Acaponeta (camarón, róbalo, lisa, jaiba y ostión) para ser vendidos en la ciudad, sí pagaban alcabala por ser considerados artículos de lujo. El superintendente de alcabalas estableció el formato de que cada vendedor pagara una cantidad anual (iguala) por el derecho de establecer cierto número de puestos en la plaza con la condición de que estos deberían de estar separados de los que ponían los indios. Es importante mencionar que cuando se fundó la aduana de Guadalajara en 1673, se estableció entre otras cosas, los horarios para que entraran las mercancías a la ciudad, solo los que introdujeran pescado fresco lo podrían hacer a cualquier hora. (Instituto Cultural Ignacio Dávila Garibi (en adelante ICIDG) Gdl 12 35). Pero además estos productos no solo se vendían en la plaza de San Agustín sino que se podían encontrar en las distintas tiendas de la ciudad durante todo el año. Por ejemplo en varios inventarios de tiendas ubicadas por varios sectores de Guadalajara es común encontrar la presencia de camarón, lisa, róbalo y ostión. Todo seco o salado.

Los regidores de la ciudad eran los encargados de establecer los precios por libra $(0.46 \mathrm{~kg}$.) en que se debían vender estos productos 
a lo largo del año en la plaza y tiendas. Se reunían en enero y mediante la consulta que hacían a varios mercaderes expertos en la materia fijaban el costo al menudeo. Si analizamos los precios de estos productos entre 1656 y 1667 notamos como el del ostión se mantiene estable en dos reales por cada libra, el del camarón seco fluctuaba entre un real y medio y dos reales la libra, mientras que el róbalo seco más barato rondaba entre un real y real y medio la libra. Teóricamente así debía de funcionar este circuito comercial, pero es de suponer que en temporada de gran demanda como semana santa el valor de estos se incrementara sin importar el precio que había fijado la autoridad.

Véase cuadro 1

Cuadro 1. Precios anuales de mariscos en reales por libra VENDidos EN Guadalajara AL MENUdeO

\begin{tabular}{|l|l|l|l|l|l|l|l|l|l|l|l|l|}
\hline & 1656 & 1657 & 1658 & 1659 & 1660 & 1661 & 1662 & 1663 & 1664 & 1665 & 1666 & 1667 \\
\hline Camarón & $0-2-0$ & $0-2-0$ & $0-1-6$ & $0-1-6$ & $0-1-6$ & $0-2-0$ & $0-1-6$ & $0-1-6$ & $0-1-6$ & $0-1-6$ & $0-1-0$ & $0-1-6$ \\
\hline Róbalo & $0-1-0$ & $0-1-6$ & $0-1-6$ & $0-1-6$ & $0-1-0$ & $0-1-0$ & $0-1-0$ & $0-1-6$ & $0-1-6$ & $0-1-6$ & $0-1-0$ & $0-1-0$ \\
\hline Ostión & $0-2-0$ & $0-2-0$ & $0-2-0$ & $0-2-0$ & $0-2-0$ & $0-2-0$ & $0-2-0$ & $0-2-0$ & $0-2-0$ & $0-2-0$ & $0-2-0$ & $0-2-0$ \\
\hline
\end{tabular}

Fuente: Actas de Cabildo de la ciudad de Guadalajara, Vol. 2.

La organización para la venta de pescado fresco dependió exclusivamente del Ayuntamiento. Esta institución estableció como punto de venta exclusivo la plaza que estaba frente al convento de San Agustín donde hoy se encuentra el teatro Degollado. Asignaba a un indeterminado número de funcionarios llamados procuradores quienes se encargaban de vigilar el buen funcionamiento del mercado y resolver cualquier problema que se suscitara. Eran los que asignaban los lugares de los puestos dentro de la plaza acomodándolos de acuerdo a los víveres que se vendían y separando siempre a los vendedores españoles de los indígenas. Pero quizá el mayor problema al que se enfrentaron las autoridades del cabildo de Guadalajara entorno al aseguramiento de bastimentos para los ciudadanos fue el de la regatonería pues había muchos acaparadores 
que salían de la ciudad para comprar toda la mercancía a los arrieros y después la revendían a precios altísimos. Buscaron sin mucho éxito asegurar que los víveres llegaran directamente a la plaza introducidos por los arrieros para que el común de la gente los comprara en ella a los mejores precios. El plano 1 muestra la ubicación de la plaza donde se vendían entre otras cosas, los pescados y mariscos durante 170 días al año.

Plane 1. La Ciudad de Guadalajara en 1732

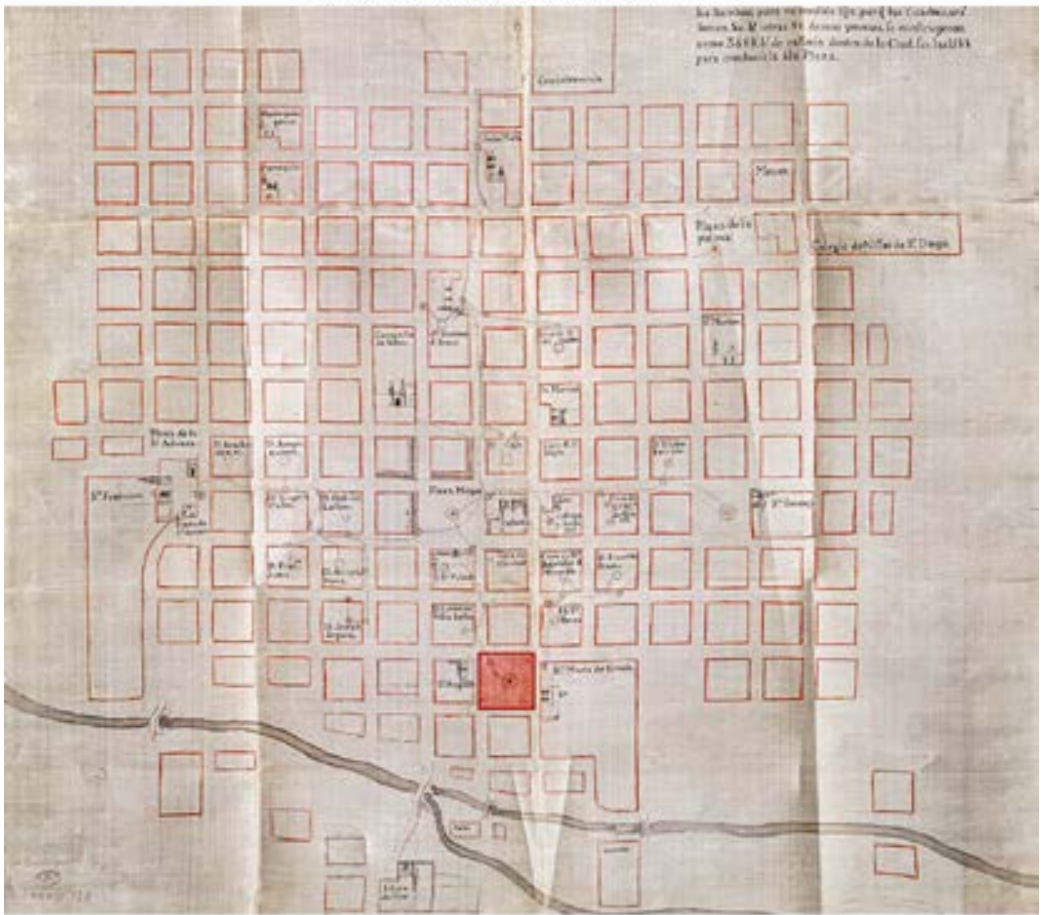

Fucate. AGI, ES 41091 .AGI27.17//MP-MEXICO, 127

Para comprobar el poco éxito que las autoridades del Ayuntamiento de Guadalajara tuvieron para extinguir la regatonería en los víveres resalto una carta de 1776 en donde el alcalde ordinario de primer voto de la ciudad pide la ayuda del presidente de la Audiencia. En ella le expresa: 
"es tanto el exceso que hay en esta materia que aún la simplicidad de los indios e indias se vale ya de este detestable arbitrio en tanto grado que pollos, peces (sic), legumbres, frutas y hasta el pimiento verde padecen de una hora a otra tal alteración que no los logra de primera mano el que no mañanea mucho, pues en la distancia de una o dos horas sube el doble el valor de cada especie. Los pobres y toda la ciudad de queja." (BPEJ-RAGCivil 446-10-7358).

Desde cien años atrás, en 1671 el fiscal de la audiencia y otras autoridades habían escrito exactamente lo mismo sobre los problemas que ocasionaban el acaparamiento y reventa de víveres. Pero desde tiempo atrás los castigos y penas implementadas por el Cabildo para evitarlas de nada sirvieron a pesar de que año con año se mandaba pregonarlas. ${ }^{5}$

\section{CONFLictos ENTORNO A LA INDUSTRIA PESQUERA}

La importancia económica que alcanzó la industria pesquera para el abasto de los grandes centros consumidores como Guadalajara, no estuvo exenta de conflictos ocasionados por el afán de explotar las fuentes de abastecimiento, por la regatonería (reventa), acuerdos incumplidos de venta y la imposición del cobro de impuestos. En el primer rubro es común encontrar quejas de indios de distintos pueblos porque las autoridades o ciertos españoles les impedían realizar la pesca y venta. Esto a pesar de que cuando la Audiencia otorgaba una licencia para establecer una pesquería lo hacía con la condición de que se permitiera a los naturales la libre pesca ${ }^{6}$ y de que ordenaba a los alcaldes mayores y corregidores que no pusieran trabas a los indios para realizar esa actividad.

En 1671 por ejemplo todos los vecinos y naturales del pueblo de Acaponeta se quejaron ante el presidente de la audiencia de Guadalajara de que su alcalde mayor le impedía la pesca y venta de sus productos porque no se los vendían a él sino a otras personas. Se le ordenó que suspendiera esa imposición so pena de 500 pesos. (AIPG, Libros de Gobierno, vol. 1, exp. 176, fojas 142f-143f). 
Llegó a darse el caso de pueblos donde sus habitantes que se dedicaban a esta actividad económica desde tiempos prehispánicos, se vieron forzados ya en el siglo XVIII a solicitar que se les permitiera continuar haciéndolo en espacios que antes habían sido suyos. Una muestra de lo anterior ocurrió en 1774 cuando los naturales del pueblo de Jamay acudieron ante el presidente de la Audiencia de Guadalajara para pedirle que el español Miguel del Portillo no les impidiera pescar a la orilla de la laguna de Chapala como lo venían haciendo desde tiempos inmemoriales. (BPEJ-RAG-Civil 90-161007). Misma situación enfrentaron los habitantes del pueblo de Ajijic quienes en 1791 pidieron el amparo de la Audiencia por la posesión de una orilla de la citada laguna. Ellos querían seguir pescando charal pero el español Agustín Miguel los quería despojar de ella. (BPEJ-RAG-Civil 364-6-5439). Lo que en realidad ocurrió es que la inserción de los españoles en el negocio de la pesca fue desplazando gradualmente a muchos indígenas o afectando sus fuentes de abastecimiento por el uso que los peninsulares hacían de ellas.

Hacia 1675 los indígenas de los pueblos de Cajititlán, Tlajomulco, Cuyutlán y San Lucas recibieron un fuerte descalabro cuando perdieron un pleito que tuvieron con el dueño de la hacienda de Los Cedros. Este personaje solicitó una merced para sacar agua de la laguna de Cajititlán con el fin de regar sus sembradíos de trigo a lo cual se opusieron los gobernadores de esos pueblos argumentando que se verían perjudicados en su pesca de charal que realizaban en los meses de enero y febrero, la cual llevaban a vender a Guadalajara y de ahí obtenían para vivir. El hacendado aportó como pruebas la amplitud de la laguna que tenía más de seis leguas de circunferencia con una profundidad de 3 a 4 varas, de manera que no afectaba a esos habitantes. Demostró también que no los perjudicaba pues los tiempos de saca de agua para regar no empataban con los de la cosecha de charal, pero sobre todo se amparó en el hecho de la constante escasez de trigo que sufrían los habitantes de Guadalajara y por lo tanto su solicitud representaba un bien público, lo que le valió ganar el pleito. (AIPG, Libros de Gobierno, vol. 2, exp. 249, fojas $340 \mathrm{f}-349 \mathrm{v}$ ). 
Otro ejemplo más de las disputas por las fuentes de abastecimiento se dio en torno a la explotación pesquera del río Grande o Santiago. Sucede que desde fines del siglo XVII y primeros ańos del XVIII el espańol Francisco Javier Delgadillo pescaba en 25 pozos o charcos de ese río en un tramo que iba desde la hacienda de Guastla hasta un vado que se formaba en un lugar llamado Santiago. Todo indica que el problema se suscitó cuando este personaje intentó incrementar su pesquería rompiendo acuerdos antes establecidos e intentando apropiarse de espacios que no eran suyos. Cuando solicitó la formal posesión de ese parte del río los primeros en oponerse fueron los naturales del pueblo de San Cristóbal de la Barranca quienes aceptaron que tenían un pacto con Francisco para permitirle la explotación de ocho charcas que se encontraban en su jurisdicción a cambio de regalarles la mitad de lo pescado pero que con la pretensión de adueñarse de ellos no lo consentirían más. Otros tres propietarios legales del espacio donde se ubicaban el resto de las charcas manifestaron el mismo rechazo argumentando que la instalación de muchos pescadores ponía en riesgo sus huertos, tierras pero sobre todo a las mujeres de sus respectivas familias. A final de cuentas Delgadillo se desistió y tuvo que abandonar el lugar perdiendo su antigua fuente de riqueza. (BPEJ-RAG-Civil 304-14381).

Definitivamente el conflicto que demuestra ampliamente la importancia económica que había adquirido la venta y consumo de pescados y mariscos en Guadalajara en la segunda mitad del siglo XVII, es el que se suscitó en 1671 cuando el recién nombrado fiscal de la Audiencia Fernando de Haro y Monterroso intentó imponer el cobro de alcabala a estos productos. Después de realizar un minucioso estudio sobre el comercio que se realizaba en la jurisdicción de la caja real de Guadalajara encontró muchos fraudes a la Real Hacienda. Uno de ellos consistía en la gran abundancia de pescado que pasaba por la ciudad para abastecer a muchas partes de la Nueva España sin que se llevara registro de ella por no existir una aduana. (AGI, Guadalajara, Cartas de Audiencia 11 R. 10 N. 62). Su objetivo primario una vez que logró la autorización para 
establecer la aduana fue el de cobrar alcabala a todo el pescado seco y salado que salía de la capital neogallega. ${ }^{7}$

La respuesta inmediata de los mercaderes y diputados del comercio de Guadalajara fue la de oponerse a esa medida argumentando que por ley la alcabala se pagaba en el lugar de la venta final y como ésta no se realizaba en la ciudad, no tenía por qué pagarse. (ICIDG, Gdl $1227)$. El fiscal por su parte replicó que era notorio que los obligados del abasto de la ciudad de México venían a comprarlo aquí y otro tanto lo llevaban los arrieros a venderlo a otras partes de la Nueva España. El conflicto duró más de un año en donde la postura de los comerciantes locales se mantuvo firme pues se sabían respaldados por la ley a pesar de la impugnación del fiscal que señalaba que debía de cobrarse aquí pues no había forma de cobrarla posteriormente porque no se sabía el destino final de la mercancía y eso representaba un gran fraude para la corona. Finalmente en 1672 el veredicto de la audiencia de Guadalajara fue a favor de los comerciantes al ordenar que no se modificara de momento la administración de las alcabalas. (ICIDG, Gdl 12 32).

El fiscal Fernando Monterroso estaba convencido de las grandes sumas de dinero que se manejaban en la venta de los pescados y de que por esta se debía pagar alcabala, por eso dos años después, ya como juez superintendente de alcabalas, retomó el asunto para intentar imponer ahora ese gravamen al pescado fresco que se consumía en Guadalajara. Respaldado en el hecho de que durante 170 días se vendía pescado fresco en la plaza de la ciudad, tomó como ejemplo a uno de los principales abastecedores para tasarle un cobro de 60 pesos por todo el año a pesar de que consideraba muy corta esa cantidad pues asumía que este vendía 16 pesos cada día lo que le daba una venta anual de 2,720 pesos y de acuerdo al $6 \%$ de alcabala, la cantidad a pagar debía ser de 172 pesos.

El afectado que era dueño de un chinchorro en la laguna de Chapala se opuso a ello explicando sus razones y presentando numerosos testigos que respaldaron sus argumentos. Toda la defensa se centró en la costumbre inmemorial de que no se cobraba alcabala a este comercio pues estaba considerado como un bien común ya 
que lo que no se vendía se regalaba a los conventos, presos y pobres de la ciudad. Lo relevante de este pleito es la sentencia que emitieron el presidente y oidores de la Audiencia ya que fue más contundente que la anterior del pescado seco pues afirmaba que el pescado fresco era de poca importancia al ser el sustento principal de la gente "pobre y miserable", además de que mucho de lo que ingresaba se repartía de limosna a los conventos y presos de la cárcel, razón esencial por la cual nunca se había cobrado ese impuesto, por lo tanto mandaron "que no se ignore la costumbre que hasta aquí ha sido".(BPEJ-RAGCivil 8-17-113).

Tenemos entonces que la misma sentencia demuestra el alto consumo entre la población de Guadalajara pues no negaba el argumento del fiscal respecto a los muchos días en que se vendía pescado en la ciudad, más bien respaldaba los asertos de los vendedores de pescado respecto a que era muy poca la ganancia por la mucha competencia que había lo que generaba que se les quedara mucha de su mercancía y entonces se veían obligados a regalarla pero a fin de cuentas lo que entraba de pescado sí se consumía en la ciudad.

\section{REFLEXIÓN FINAL}

La investigación realizada en diferentes archivos con la finalidad exclusiva de demostrar el alto consumo de pescados y mariscos por los habitantes de la ciudad de Guadalajara en el siglo XVII, permitió comprobar que al menos durante 170 días al ańo se comían estos productos y no solamente durante el periodo de cuaresma. Lo anterior se debió al alto número de días de vigilia y fiestas de guardar al año en donde la comida principal consistía en pescados. Es fácil imaginar que durante la cuaresma la población comía estos productos, pero no se sabía que 130 días más lo hacían debido también a cuestiones de fe. Pero además, como se pudo constatar por el libro de cuentas de los agustinos, estas viandas en particular los mariscos estaban presentes en fiestas especiales, lo que lleva a suponer que algo parecido ocurría en el resto de los conventos de la ciudad, aunque faltaría comprobarlo si existiesen libros de cuentas 
similares. Con ello se comprueba el argumento principal de este artículo al dar certeza del alto consumo entre los habitantes de Guadalajara en aquella centuria.

La historia del abasto y consumo de pescados y mariscos en Guadalajara durante la colonia es tan amplia que el contenido en este artículo viene a representar apenas un bosquejo. Muchos temas surgen y se antojan para analizarlos a mayor detalle como por ejemplo las cantidades consumidas y sus precios a partir de localizar más libros de cuentas de tiendas, tendajones, pulperías o de conventos. Los costos de traslado, la capacidad de carga de las mulas, salarios de los arrieros, formas de realizar la conserva mediante la salación o el secado quedan también como propuesta para futuros estudios. Queda pendiente rescatar la historia de la actividad pesquera de los indígenas tanto para su consumo interno como para su inserción como abastecedores en un mercado que fue adquiriendo a través del tiempo mayor relevancia económica. Debido a lo anterior será importante conocer las problemáticas que vivieron ante competidores espańoles que actuaban como revendedores y controlaban los mercados urbanos. El desplazamiento paulatino de los pescadores indígenas por parte de los españoles es otro tema interesante para trabajar a futuro siempre y cuando existan fuentes al respecto.

Se antoja profundizar en el tema fiscal vinculado a este circuito comercial pues aunque se demostró que debido a la importancia económica que alcanzó este comercio, el fiscal superintendente de alcabalas se vio precisado a imponer el cobro de alcabala mediante el sistema de igualas a aquellos productos venidos del mar y que eran considerados artículos de lujo, mientras que los que provenían de la laguna de Chapala y del río Grande quedaron exentos por ser para pobres. Conocer los montos recaudados de esas igualas parece de momento imposible porque no hay libros fiscales de la Nueva Galicia para el siglo XVII. Sería posible conocer esas cifras para la siguiente centuria mediante un largo trabajo de archivo revisando los libros que si existen para ese tiempo y podría servir para tratar de indagar en qué momento se modificó el sistema alcabalatorio para unificar el pago de todos los pescados y mariscos. 
Los temas anteriores son solo una muestra de lo mucho que se puede investigar sobre el circuito comercial de los pescados y mariscos en la Nueva Galicia durante la época colonial aspecto tan importante pero tan desconocido que toma mayor relevancia si lo vinculamos a la problemática actual donde muchas de las especies comerciadas o lugares de abastecimiento coloniales ya no existen.

\section{BibliografíA}

ACUÑA, René (ed.), (1982). Relaciones geográficas del siglo XVI: La Nueva Galicia. México: Universidad Nacional Autónoma de México.

ARREGUI, Domingo. (1980). Descripción de la Nueva Galicia. Guadalajara: Unidad Editorial del Gobierno del Estado de Jalisco.

ASSADOURIAN, Carlos. (1983). El sistema de la economía colonial. El mercado interior, regiones y espacio económico. México: Editorial Nueva Imagen.

Boletín del Archivo General de la Nación (1937). “Nuño de Guzmán contra Hernán Cortés sobre los descubrimientos y conquistas en Jalisco y Tepic 1531”. Tomo VIII, núm. 3, pp. 365-576.

BORAH, Woodrow. (1994). Tendencias de precios de bienes de tributo real en la Nueva Galicia, 1557-1598. México: El Colegio de Jalisco, El Colegio de Michoacán.

CALDERON, Andrés. (2016). Mirando a Nueva España en otros espejos. Cuatro ensayos sobre demografía y niveles de vida, siglos $X V I-X I X$. Memoria para optar por el grado de doctor. Madrid: Universidad Complutense de Madrid, Facultad de ciencias económicas y empresariales, Departamento de Historia de las Instituciones Económicas II.

CALVO, Thomas. (1992). Guadalajara y su región en el siglo XVII. Población y economía. Guadalajara: Ayuntamiento de Guadalajara.

CUBILLO, Ramón. (1998). El pescado en la alimentación de Castilla y León durante los siglos XVIII y XIX. León: Universidad de León, Secretariado de Publicaciones. 
DE LEÓN, René. (2016). "El Cultivo del trigo en Nueva Galicia durante el siglo XVII". Secuencia núm. 94, pp. 39-76.

FLORESCANO, Enrique y Gerardo SÁNCHEZ. (Ed.), (2018). El pescado blanco en la historia, la ciencia y la cultura michoacana. Morelia, Gobierno del Estado de Michoacán, Secretaría de Cultura, UMSNH, Instituto de Investigaciones Históricas.

GARAVAGLIA, Juan y Juan GROSSO. (1994). Puebla desde una perspectiva microhistórica. La villa de Tepeaca y su entorno agrario: población, producción e intercambio (1740-1870. México: Editorial Claves Latinoamericanas.

GARAVAGLIA, Juan y Juan GROSSO. (1987). "El abasto de una villa novohispana: mercancías y flujos mercantiles en Tepeaca (1780-1820)”. Anuario IEHS, vol. 2, pp. 217-253.

LAVRIN, Asunción. (2016). Las esposas de cristo. La vida conventual en la Nueva España. México: Fondo de Cultura Económica.

LORETO, Rosalva. (2000). Los conventos femeninos y el mundo urbano de la Puebla de los Ángeles del siglo XVIII. México: El Colegio de México.

MARCHENA, José. (2010). La vida y los hombres de las galeras de España (siglos XVI-XVII). (Tesis de doctorado inédita). Universidad Complutense de Madrid, Facultad de Geografía e Historia. España.

MOTA, Alonso. (1993). Descripción geográfica de los reinos de Nueva Galicia, Nueva Vizcaya y Nuevo León. Guadalajara: Gobierno del Estado de Jalisco, Universidad de Guadalajara.

MOTA, Matías. (1993). Historia del reino de la Nueva Galicia en la América Septentrional. Guadalajara: Universidad de Guadalajara.

MEIJIDE, Antonio. (1980). El comercio de bacalao en la Galicia del siglo XVIII. La Coruña: Diputación provincial de la Coruña.

PERALTA, Alberto. (2018). "Las cocinas de los monasterios franciscanos novohispanos del siglo XVI. Génesis del mestizaje gastronómico de México". Culinaria revista virtual especializada en gastronomía, núm. 15, pp. 21-37.

PIQUERO, Santiago y LÓPEZ, Ernesto. (2008). "El consumo 
de pescado en España. Siglos XVIII-XX. Una primera aproximación". www.sehainfo/iii economia/III.piquero.pdf.

QUIROZ, Enriqueta, (2005). Entre el lujo y la subsistencia. Mercado, abastecimientos y precios de la carne en la ciudad de México, 1750-1820. México: El Colegio de México, Instituto Mora.

QUIROZ, Enriqueta. (2014). "Comer en Nueva Espańa. Privilegios y pesares de la sociedad en el siglo XVIII". Historia y Memoria, núm. 8, pp. 19-58.

REYNOSO, Abril. (2016). "Comer para sanar: alimentación y medicina en Nueva Galicia, s. XVIII”. Relaciones Estudios de Historia y Sociedad, vol. 37, núm. 146, pp. 47-81.

RUEDA, Laura. (2009). "Corredores de abasto indígena en la Nueva Galicia: un modelo regional de mercado. Sociedad y comercio colonial durante los siglos XVI y XVII". En LONG, Janet y Amalia, ATTOLINI (coord.). Caminos y Mercados de México. México: Universidad Nacional Autónoma de México, Instituto Nacional de Antropología e Historia, pp. 327-348.

SERRERA, Ramón. (1974). "Estado económico de la intendencia de Guadalajara a principios del siglo XIX: La relación de José Fernando de Abascal y Sousa de 1803". Anuario de Historia de América Latina, vol. 11, pp. 121-148.

SERRERA, Ramón, (1992). Guadalajara ganadera: estudio regional novohispano, 1760-1805. Guadalajara: Ayuntamiento de Guadalajara.

TORRIJA, María. (2009). "La alimentación en la época de la guerra de la independencia”. Anales de la Real Academia Nacional de Farmacia, núm. 5, pp. 613-638.

VÁZQUEZ, Antonio. (1948). Compendio y descripción de las Indias Occidentales. Washington: Smithsonian Institution.

VÁZQUEZ, José. (2009). Sabrosa abstinencia. Abasto y consumo de pescado en el monasterio de sobrado (ss. XVII-XVIII). Obradorio de Historia Moderna, núm. 18, pp. 151-179. 
Fuentes

AGI

AGNM

Archivo General de Indias

BPEJ-RAG

Archivo General de la Nación de México

Biblioteca Pública del Estado de Jalisco, Real

Audiencia de Guadalajara

AIPG

Archivo de Instrumentos Públicos de Guadalajara

ICIDG

Instituto Cultural Ignacio Dávila Garibi

AHMG

Archivo Histórico Municipal de Guadalajara.

Notas

${ }^{1}$ Ejemplo de lo anterior son los trabajos de Garavaglia y Grosso (1987 y 1994) para la región de Tepeaca en Puebla; los de Enriqueta Quiroz (2005 y 2014) para la ciudad de México, el de Calderón (2016) para toda la Nueva España. Varios estudiosos de la vida conventual en México han señalado la fuerte presencia del consumo de pescados y mariscos en esos lugares. (Peralta, 2018), (Lavrin, 2016) y (Loreto, 2000) entre otros. La reciente obra de Florescano y Sánchez (1018) sobre el pescado blanco en Michoacán resalta como un caso de lo que se puede estudiar entorno a esta temática.

${ }^{2}$ Todo lo contrario al constante padecimiento que sufrió (ya fuera por causas naturales o de corrupción) por la escasez de granos (trigo y maíz) y animales (ganado mayor y menor). En un artículo publicado años atrás explico las causas de esta carestía (De León, 2016).

${ }^{3}$ Sobre la forma de trasladar mariscos desde Centipac y capacidad de carga de las mulas, véase BPEJ-RAG-Civil 310-214518. Sobre los costos de traslado de Tepic a Guadalajara BPEJRAG-Bienes de Difunto 62-1-792.

4 BPEJ-RAG-Civil 8-17-113. En Castilla durante el siglo XVIII los días de venta de pescado sumaban 120 al año mientras que en Aragón sobrepasaban los 160 (Cubillos, 1998, pp. 6-7).

5 Sobre las quejas del fiscal y otras autoridades ver BPEJRAG-civil 12-8-163 y AIPG, Libros de Gobierno, vol. 1, exp. 159 , f. 123f-126f. Los mandamientos y penas que impuso durante 
todo el siglo XVII el Ayuntamiento pueden consultarse en Actas de Cabildo de la ciudad de Guadalajara, 2 vols.

${ }^{6}$ En 1646 se le otorgó a Pedro Ávalos y Bracamonte una merced de pesquería en la provincia de Centipac con la condición de que no impidiera que los naturales de los pueblos de Iscuintla y San Andrés pescaran en aquellos esteros. BPEJ-RAG-Bienes de Difunto, 263-4-2880.

${ }^{7}$ La venta de pescado salado que cruzaba por Guadalajara presenta cierta similitud con la exportación de ganado mayor en cuanto a que mucho de lo que se sacaba pasaba por la capital de ese reino. La diferencia era que en la saca de animales sí se llevaba un registro para cobrar un impuesto que estaba determinado por el número de cabezas que salían, en cambio con el pescado salado no se registraban las cantidades y mucho menos se tenía establecido algún impuesto por concepto de exportación.

FECHA DE RECEPCión: 1 de septiembre de 2020

Fecha de Aceptación: 23 de noviembre de 2020

Versión Final: 26 de noviembre de 2020 